\title{
Dissertações e Teses do Programa de Pós-Graduação em Antropologia e Arqueologia da UFPR - 2020
}

\section{TESES}

Título: Etnografia de um direito: o estabelecimento de uma política de acesso de quilombolas à Universidade Federal de Santa Catarina

Autoria: Judit Gomes da Silva

Orientadora: Ciméa Barbato Bevilaqua

Resumo: Esta tese é um estudo etnográfico dos processos de constituição, aprovação e implementação de vagas suplementares para estudantes quilombolas em cursos de graduação da Universidade Federal de Santa Catarina (UFSC). A descrição busca evidenciar a constituição do direito de quilombolas ingressarem à universidade a partir da confluência entre, de um lado, os processos de reivindicação e estabelecimento de ações afirmativas no país e na UFSC e, de outro, o reconhecimento de direitos territoriais quilombolas pela Constituição Federal de 1988 e alguns de seus desdobramentos - em especial a luta por uma educação quilombola. Descrevo como, na UFSC, a conjunção conflituosa entre o Programa de Ações Afirmativas estabelecido em 2007 e a edição da Lei no 12.711/12, a Lei de Cotas, associada à luta de comunidades quilombolas, em aliança com o Movimento Negro Unificado (MNU/SC) e pesquisadoras da instituição, gerou a possibilidade de criação de vagas suplementares para quilombolas, aprovada pelo Conselho Universitário em 16 de junho de 2015. Ao abordar a implementação desse direito, trato de evidenciar as condições de ingresso e as experiências de estudantes quilombolas na UFSC. Minhas interlocutoras e interlocutores são de três comunidades quilombolas: Aldeia, Invernada dos Negros e Morro do Fortunato. Destaco as relações de parentesco entre elas e eles e as redes de solidariedade que, em concomitância com o direito específico, medeiam o acesso à universidade. Também descrevo os obstáculos para "ficar na UFSC", a aliança política com indígenas e as disputas junto à administração da universidade pela permanência, em uma conjuntura de retrocessos em relação às políticas da diferença.

Palavras-chave: Quilombolas; Políticas Afirmativas; Direitos à Educação; Corpos Negros; Universidade Federal de Santa Catarina. 
Título: Al Dakhel, cartografias como experiência: Reflexões a partir de um trabalho de campo na Palestina

Autoria: Rafael Gustavo de Oliveira

Orientador: Lorenzo Gustavo Macagno

Resumo: Pensar a Palestina a partir dos imperativos cartográficos impressos sobre a região, que delimitam espaços no que chamo "binômio rígido", a saber, "Palestina vs Israel", pode incorrer no ofuscamento das construções, usos e acionamentos de categorias locais de territorialidade e suas equivalências identitárias. Estas categorias, no entanto, em contraposição à tal rigidez, terminam por construir uma "Palestina única", composta por quatro espaços distintos, a Cisjordânia, a Faixa de Gaza, Jerusalém e, por último, Al Dakhel - “dentro”, ou sua variante, “48”, cujo acionamento e sentido se dá em lugar do que chamarei de categoria contrastiva, a saber, "Israel”. Dito de outro modo, a Palestina, em acordo com expressões locais de territorialidade, não se delimita, enquanto espaço, aos chamados "Territórios Palestinos". Fruto de aproximadamente dois anos de trabalho de campo, é a partir de minha vivência enquanto antropólogo e, também, como professor de violão que traço os argumentos aqui apresentados, uma vez que, alocado no corpo institucional de conservatórios de música locais, tive acesso e compus diferentes estratégias e práticas de mobilidade. No exercício de tais atividades, fui acometido da necessidade de mover-me entre, principalmente, a Cisjordânia e Jerusalém, contudo, sem desfrutar de documentos permissivos por certos períodos de tempos. Com isto, estratégias de movimento e trânsito por e entre os diferentes espaços aqui citados tornaram-se componentes de meu cotidiano. A partir disto, como apresento neste trabalho reflexivista, passei a refletir sobre mobilidade e suas inerentes complexidades locais enquanto componentes da construção desta referida "Palestina única".

Palavras-chave: Palestina; Mobilidade; Territorialidade.

Título: Indígenas na cidade: uma análise histórica e etnográfica da presença kaingang em Curitiba

Autoria: Pedro Henrique Ribas Fortes

Orientador: Ricardo Cid Fernandes

Resumo: A região do planalto curitibano apresenta um complexo e denso histórico de contatos e relações entre os indígenas e os não indígenas. Dados demográficos, históricos, etnográficos, entre outros, revelam não somente a presença de diversos contingentes indígenas nesse espaço, antes e após a presença de não indígenas, mas, também, a importância política do espaço para esses grupos, sobretudo os Kaingang. Desde o século XIX, transformaram a cidade em uma zona de contato, invertendo a lógica colonizadora que dimensionava o contato exclusivamente para os aldeamentos estrategicamente posicionados na região paranaense. Através desses mesmos esforços, territorializam e transformam a paisagem, acionando histórias e memórias que tratam da presença kaingang na cidade e nos arredores. Apesar de a passagem e a permanência na cidade serem categorias que precisam a todo tempo serem negociadas com o Estado, a história e a memória revelam seus caminhos. Qualquer viagem necessita de uma história ou narrativa prévia que lhe aponte o caminho. De outra forma, ou se está perdido, ou se explora o desconhecido. Os Kaingang que residem ou permanecem temporariamente no planalto curitibano não estão perdidos, muito menos explorando o desconhecido.

Palavras-chave: Indígenas na cidade; história indígena; Território; Kaingang. 
Título: "Unir para lutar; unificar para vencer": Um estudo etnográfico da organização indígena Federação do Povo Huni Kui do Acre - FEPHAC

Autoria: Andreia Baia Prestes

Orientador: Miguel Alfredo Carid Naveira

Resumo: Este trabalho trata da Federação do Povo Huni Kuĩ do Acre - FEPHAC, uma organização indígena que atua em prol da união, autonomia e autodeterminação do povo Huni Kuĩ, mediante o fortalecimento institucional e representativo de sua organização perante o Estado não-indígena e os próprios Huni Kuĩ. Para tanto, a pesquisa dedica-se aos tempos cronológicos que compõe a história dos povos indígenas do Acre, a partir do ponto de vista Huni Kuĩ, para então abordar a Federação, analisando os motivos pelos quais foi criada, e o contexto político em que isso ocorre. Em seguida, será apresentada a forma como a instituição se constitui nos eventos que promove, nas pessoas que trabalham nela e nos documentos e discursos que produz.

Palavras-chave: Organização indígena; Autodeterminação; Representatividade; Fortalecimento jurídico-político.

\section{DISSERTAÇÕES}

Título: À procura da intenção: uma etnografia do Setor de Vulneráveis da Polícia Civil do Paraná.

Autoria: Eduardo Oliveira de Almeida

Orientadora: Ciméa Barbato Bevilaqua

Resumo: O objetivo deste trabalho é abordar a constituição dos crimes contra vulneráveis investigados pelo Setor de Vulneráveis da Divisão de Homicídios e Proteção à Pessoa da Polícia Civil do Paraná. O Setor é responsável por apurar crimes dolosos cuja motivação seja discriminação ou preconceito de cor, raça ou etnia, religião, procedência nacional, idade, identidade de gênero, orientação sexual, bem como em razão de a pessoa ser deficiente ou estar em situação de rua. $\mathrm{O}$ trabalho é fruto de uma pesquisa etnográfica realizada nas dependências dessa unidade entre março e outubro de 2019. Para abordar o tema, privilegiou-se o modo como os casos se constituíam enquanto atribuição da polícia, ou seja, como eram noticiados, investigados e concluídos pelo trabalho de investigação policial. A existência de uma unidade exclusiva para tais casos, a legislação que os tipifica e o trabalho policial de apuração dos crimes ganham destaque para compreender a constituição dos crimes investigados pelo Setor. Tais crimes dependiam também da comprovação do dolo específico, que diz respeito a uma motivação exclusiva e intencional de discriminar. Assim, a procura por uma intenção unívoca dos investigados se estabelece como um elemento central e de destaque para compreender o modo pelo qual os crimes contra vulneráveis constituem-se nas dependências do Setor que deles se ocupa.

Palavras-chave: Etnografia; Investigação policial; Crime de racismo; Injúria racial; Dolo específico.

Título: Aprendimos mucho de agricultura em 35 años: soja e trabalho entre os Aché de Puerto. Barra, Paraguai. 
Autoria: Pedro Henrique Frasson Barbosa

Orientadora: Edilene Coffaci de Lima

Resumo: O presente trabalho é um estudo etnográfico da produção de soja dos Aché da comunidade de Puerto Barra, localizada no departamento paraguaio de Alto Paraná. Desde meados da década de 1970 vivendo aldeados junto a família missionária Fostervold, os Aché Nacunday ou Yñaro gradativamente se transformaram de um povo predominantemente caçador-coletor não praticante da agricultura em um grupo que, duas vezes ao ano, cultiva uma grande quantidade de soja em seu território. Esta investigação diz respeito ao ciclo da safrinha de soja do ano de 2019, que foi plantada pelos Aché e cujo trabalho ocorreu centrado especialmente em duas famílias. A colheita e o transporte dos grãos foram realizadas por um vizinho brasiguaio, uma vez que os Aché não possuem o maquinário necessário para o serviço. Os recursos advindos da venda da produção de soja são empregados essencialmente na preparação diária de um almoço servido a todas as pessoas da aldeia, na manutenção do próprio ciclo da soja e na continuidade de outras atividades internas. Ninguém recebe um salário para trabalhar com a soja em Puerto Barra, ou seja, mesmo que as atividades aconteçam a partir de algumas famílias, os recursos advindos da venda da produção não se aglutinam em grupo familiar algum. Além das ocupações internas, uma grande parte das pessoas que vivem na aldeia também realizam trabalhos temporários fora da comunidade, nos vizinhos paraguaios, brasiguaios e alemães. De maneira diferente ao passado, manifestam alguns interlocutores, na vida fora da floresta é preciso de dinheiro para continuar existindo. Palavras-chave: Aché (Ñacunday,Yñaro). Caçadores-coletores. Agricultura indígena. Paraguai. Guarani.

Título: Quilombo Brotas de Itatiba (SP): significados, interpretações, memórias e consciência quilombola

Autoria: José Roberto Barbosa

Orientador: Ricardo Cid Fernandes

Resumo: Esse trabalho tem por objetivo refletir sobre o Quilombo Brotas, comunidade à qual pertenço, e que está localizada no município de Itatiba no estado de São Paulo. A pesquisa enfocou a análise das interpretações e as relações dos atuais quilombolas com o que muitas vezes é denominado “os Antigos” e “o Antigamente”. Especial atenção foi dada à relação com a memória de Amélia Gomes de Lima Barbosa, mais conhecida como "Vó Mélia", ancestral a partir da qual os quilombolas do Quilombo Brotas procuram fundamentar sua legitimidade e seu direito ao território. A análise também considera o imaginário de muitas pessoas que visitam e/ou estudam o Quilombo Brotas sobre a figura de "Vó Mélia" e sobre a estrutura social da comunidade. A partir do Quilombo Brotas, a reflexão abarca o fenômeno dos Quilombos contemporâneos, as representações sociais sobre Quilombos e quilombolas e a forma como estas representações podem afetar a luta das atuais comunidades quilombolas por reconhecimento. A análise inclui, ainda, considerações sobre o desenvolvimento histórico do conceito de Quilombo, suas expansões metafóricas e a possibilidade de se pensar uma base para a conceituação de Quilombo e quilombola que não se encontre refém das representações, as quais são frequentemente baseadas em estereótipos e idealizações. Por fim, a pesquisa propõe que, devido a seu histórico e 
particularidades contemporâneas, o Quilombo Brotas e seus quilombolas podem ser encaixados em diversos desses conceitos de Quilombos desenvolvidos ao longo do tempo.

Palavras-chave: Quilombo; Representação Social; Identidade; Ancestralidade; Itatiba.

Título: Artesanato Mbyá-guarani na comunidade de Yriapú

Autoria: Kauana Maria Santos Neves

Orientador: Marcos Silva da Silveira

Resumo: A presente dissertação é uma etnografia sobre a produção artesanal que acontece na comunidade Mbyá-Guarani Yriapú, localizada na cidade de Puerto Iguazú, no estado de Misiones, Argentina. Para isso buscou-se realizar um breve histórico a respeito da ocupação da região pelos Mbyá-Guarani e as transformações que passaram suas práticas para que se compreendesse o atual contexto artesanal. Posteriormente foram problematizados a partir da antropologia da arte os conceitos de "arte" e "artesanato". A elaboração e confecção do artesanato por artesãs e artesãos Mbyá encontra seu predicado na mitologia, onde Nhanderú, responsável pela criação dos objetos verdadeiros ( y’pará) e contidos é contrariado pelo demiurgo Chariã quando ele decide fazer cópias (ta’anga) em arranjos mais complexos dos grafismos e artesanatos de Nhanderú. Esta situação é responsável pela fundação da humanidade (ASSIS, 2006). Ademais de descrever a produção artesanal, foi possível identificar de que maneira ela se relaciona com contextos não Mbyá em que está inserida. Através da observação participante foi possível identificar tal produção enquanto um sistema de ação (GELL, 2016) que se relaciona fortemente com contextos normatizados junto ao Estado a respeito de sua exposição e venda. A partir da progressão etnográfica, observou-se a questão do patrimônio e sua relação com os artesanatos Mbyá através da utilização do termo por diferentes atores, foi preciso então situar este pulsante elemento que possibilita outros olhares sobre o artesanato Mbyá frente o estado argentino.

Palavras-chave: Artesanato; Arte; Mbyá-guarani; Yriapú; Misiones; Patrimônio.

Título: Mulheres da Ponta Oeste: memória e territorialidade na ilha do Mel

Autoria: Renata Beghetto Pacheco

Orientador: Ricardo Cid Fernandes

Resumo: Localizada na Ilha do Mel, litoral do Paraná, a comunidade da Ponta Oeste, vizinha do Porto de Paranaguá, teve seu território limitado por uma Unidade de Conservação Integral na década de 80, pelo estado do Paraná, medida que causou um conflito territorial. Por isso, falar sobre seus indivíduos é também falar sobre esse conflito presente até os nossos dias. Isso posto, a pesquisa propõe compreender as categorias de território e as soluções encontradas por essa comunidade para afirmar o seu saber-fazer, sua memória e identidade, a partir da etnografia das mulheres, produtoras de ostra e líderes da associação de nativos da Ponta Oeste, frente às pressões e aos impactos ambientais provenientes do Porto de Paranaguá e dos embargos infligidos pelo estado do Paraná a essa coletividade. Palavras-chave: Unidades de Conservação da Natureza; Conflitos Socioambientais; Populações Tradicionais; Ilha do Mel; Maricultoras; Participação Social.

Palavras-chave: Unidades de Conservação da Natureza; Conflitos Socioambientais; Populações Tradicionais; Ilha do Mel; Maricultoras; Participação Social. 